\title{
Patients Need a Competent Pharmacist for a Safe and Successful Therapy
}

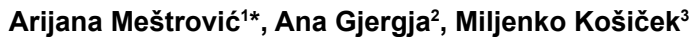 \\ ${ }^{1}$ Education Centre and Competency Development, Atlantic FARMACIA, Zagreb, Croatia \\ ${ }^{2}$ FARMACIA Community pharmacy, Zagreb, Croatia \\ ${ }^{3}$ PLIVA Croatia Ltd., Global IT - Shared Service Centre, Zagreb, Croatia
}

\begin{abstract}
Purpose

Understanding important facts about medicine therapy is needed to improve patient safety and therapy outcomes. Media advertising of medical products draws the patient's attention to the importance of reading the patient information leaflet. Despite this, some patients interrupt or change their therapy without prior consultation with a health care professional.

The purpose of this study was to examine if patients read the leaflet, if they understand it, and in case of any doubts, if they consult to a pharmacist or doctor for advice.

Methods

Responses to a patient questionnaire $(n=708)$, designed specifically for this study, were analysed to compare patient attitudes towards medical information. The survey was conducted in 55 pharmacies in Croatia in February 2010.

\section{Results}

$95.2 \%$ of those surveyed stated that they read the patient leaflet when using a medicinal product for the first time. The meaning of "contraindication" was known to $37.7 \%$ patients, and "interaction" to $65.4 \%$. Furthermore, the term "side effects" was understood by $91.8 \%$ patients of those surveyed, $74.6 \%$ of patients consulted a doctor or pharmacist for advice in case of doubts after reading the leaflet, while $78.2 \%$ of patients interrupted or changed their therapy without prior consultation with a health care professional.

\section{Conclusion}

Informing patients about medicinal products through a leaflet could be insufficient for successful therapy. The patient information leaflet should be easily understandable for the patient. The identification of patient needs for information, education and consultation about proper drug administration is a key pharmacist competency that is still to be developed.
\end{abstract}

Keywords: Patient-Centred Care; Patient Safety; Competent Pharmacists; Patient Education; Performance Measures

\section{Introduction}

\section{Advertising of medicinal products and medical devices}

The advertising of medicinal products and therapeutic preparations has long been established in mass media communications. A significant amount of space in medical journals is reserved for advertising medicines and OTC preparations. In the US, $96 \%$ of medicinal journals contain advertisements. In $88 \%$ of journals, individual advertisements took up more than one page [1]. However, the promotion of medicines occurs not only in medical journals, but also largely in popular magazines, newspapers and television [2]. Each advertisement is based on a promise; it does not sell a drug to patients but hope for their recovery. In the course of advertising, the patients' attention is drawn to the importance of reading the patient information leaflet, and they are also referred to additional consultation with a their doctor or pharmacist.

\section{What do patients expect from the patient information leaflet?}

Previous studies have shown that patients expect improvements from long-term medication administration, and stressed the importance of precise statements in the patient leaflet regarding all possible indications, side effects and contraindications for medicines. However, in order to attain effective communication with patients and their understanding of the therapy, such a list should contain larger font, headings and easier-to-understand terminology [3].

On the other hand, the majority of patients only read the patient information leaflet for OTC drugs before the first use or after already experiencing a side effect of the medicine. The most frequent reason stated for this was the excessively long list of side effects in the patient leaflet [4].

Patients are often assumed to know how to properly take medicines. However, though some facts are assumed as already established or

*Corresponding author: Arijana Meštrović, Education Centre Farmacia, Heinzelova 47B, 10000 Zagreb, Croatia, Tel: 0038591-6307116; Fax: 0038512362858; E-mail: arijana.mestrovic@atlantic.hr

Received December 30, 2011; Accepted February 08, 2012; Published February 14,2012

Citation: Meštrović A, Gjergja A, Košiček M (2012) Patients Need a Competent Pharmacist for a Safe and Successful Therapy. Adv Pharmacoepidem Drug Safety 1:104. doi:10.4172/2167-1052.1000104

Copyright: (c) 2012 Meštrović A et al. This is an open-access article distributed under the terms of the Creative Commons Attribution License, which permits unrestricted use, distribution, and reproduction in any medium, provided the original author and source are credited. 
even highlighted on medicine packages (such as maximum daily dose for paracetamol-containing drugs), such knowledge is very often insufficient for safe use. Proper informing about medicines could be conducted by more appropriate leaflet labelling [5]. The information found in the patient leaflet is most often the patient's only source of education. Very often, patients decide on the basis of these data alone about the balance between benefits and risks of product use, and of how to use it in a safe way. However, such information is often too complicated to understand, and many patients cannot easily read and comprehend the information due to the small print, large amount of information, and use of professional terms [6].

\section{Consumption of medicinal products and medical devices in Croatia}

The share of health expenditure in GDP (Gross Domestic Product) in the Republic of Croatia amounts to almost $10 \%$. According to data of the Croatian Public Health Institute, the value of prescriptions issued in the Republic of Croatia increased 4 to 5 million Euros each year in the period 2001-2005. The use of medicinal products, especially among elderly patients, is wide spread. Previous studies demonstrated that an elderly patient used an average of 4 to 5 prescription medicines and at least two OTC drugs. The largest share of prescribed medicines was for cardiovascular drugs (37.66\%) [7]. The simultaneous use of five medicinal products increases the possibility of interactions by $50 \%$, which a fact of utmost importance [8].

Some studies from Sweden show that drug use increased with advancing age, poorer health condition, greater body weight and higher level of education [9]. When discussing the younger population, the criteria vary somewhat. Adolescents, predominantly students, most frequently use medicines that are most widely advertised. The majority have been shown to take medicines without consulting a doctor [10]. From the patient perspective, there is strong evidence that communication and collaborative practice can be improved by strengthening policy and supporting healthcare professionals in disclosing adverse events. Increased openness and honesty following adverse events can improve provider-patient relationships [11].

Based exactly on these findings, we designed a study aimed at defining whether patients read the patient information leaflets at all and how often they do so, and whether they understand the basic terminology and professional terms within. We also wanted to investigate whether they consult a doctor or pharmacist in case of any doubts after reading a leaflet and, finally, do they change or interrupt their therapy on their own based on information they found in the leaflet. The intention was to apply the obtained data to enhance pharmacist awareness about the importance of ensuring proper understanding of the patient information leaflet within the scope of providing medical care through communication with the patient. Although pharmacists, during their professional education, are additionally educated for their role as consultant regarding proper medicine use and therapy administration, this competency is still insufficiently applied in pharmacies, due to the assumption that all patients read and understand the patient information leaflet [12].

\section{Methods}

\section{Instrument}

The trial was conducted through a survey in 55 Croatian pharmacies in the first half of February 2010. The selected pharmacy chain was deemed suitable due to the structure of its pharmacies, which have sufficient diversity needed for this study. This sample included pharmacies situated in different Croatian regions, in both small and large towns. At the time of filling a prescription or buying an OTC product, the patient was asked to fill out a short questionnaire, accompanied by instructions indicating that participation is completely voluntary and anonymous, and that the purpose is the improvement of medical care provided for patients.

Questions Q1-Q4 and Q8-Q10 were yes/no type questions, while questions Q5-Q7 were multiple choice questions with three options. If they circled the exact answers (Q5- a, Q6-b, Q7-a), the answer "yes" was recorded, meaning that the examinees understood the terms, while in all other cases the answer "no" was recorded.

\section{Data analysis and statistics}

A total of 708 questionnaires were filled out throughout Croatia. Of the total, 264 (37\%) examinees were men and 444 (63\%) women aged from 18 to 87 (Figure 1). Statistical analysis was performed using Statistics 6.1 software package. Statistical difference was tested at the level of significance of $95 \%$. A p value of less than 0.05 ( $p<0.05$ ) was considered statistically significant. Statistical analysis of questions Q9 and Q10 included only examinees who answered "yes" to Q8.

\section{Results}

The results indicate that $83.9 \%$ of examinees read the leaflet prior to first use (Table 1) women read it in $89.9 \%$ of cases, as opposed to men who read it in only $75 \%$ of cases, demonstrating a statistically significantly difference (Table 2).

The majority (95.2\%) of examinees knew the product being dispensed. $66.9 \%$ of men reported knowing the potential side effects of the drug, while for women; this figure was as high as $79.8 \%$. The difference between males and females on this issue was also statistically significant (Tables 1,2).

To investigate the patient's understanding of the patient information leaflet, examinees were required to identify the meaning of the three important terms: "side effect", "interaction" and "contraindication". Knowledge of the term "side effect" was highest, with as many as $91.8 \%$ of examinees answering correctly; however, examinees were not as well acquainted with the other two terms. Only $65.4 \%$ knew the meaning of the term "interaction", and only $37.7 \%$ knew the meaning of the "contraindication" (Table 1). As many as $38 \%$ could not differentiate between the terms "contraindication" and "side effect", which was evident due to the same responses given for each term.

Examinees were required to answer if, while reading a leaflet, they observed that a use of this drug would not be beneficial or safe for

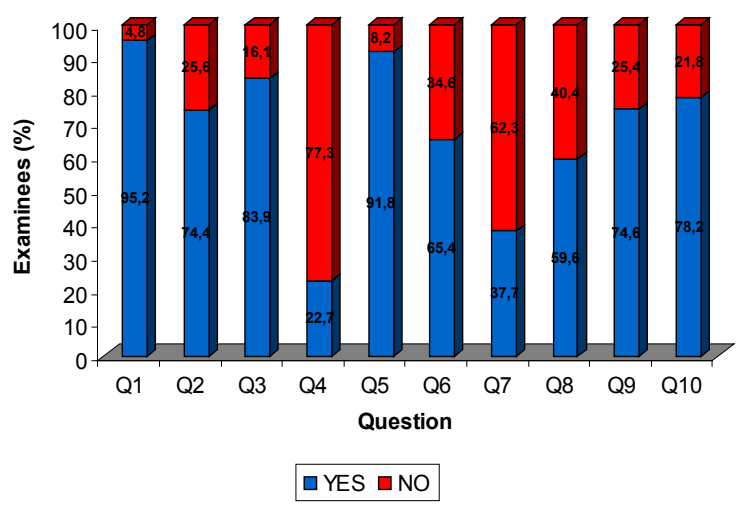

Figure 1: Summary frequency table for all questions. 


\begin{tabular}{|l|l|l|l|l|l|}
\hline Question & YES & \multicolumn{3}{l}{ NO } & Total \\
\cline { 2 - 4 } & Count & $\%$ & Count & $\%$ & \\
\hline Q1 & 674 & 95.2 & 34 & 4.8 & 708 \\
\hline Q2 & 527 & 74.4 & 181 & 25.6 & 708 \\
\hline Q3 & 594 & 83.9 & 114 & 16.1 & 708 \\
\hline Q4 & 161 & 22.7 & 547 & 77.3 & 708 \\
\hline Q5 & 650 & 91.8 & 58 & 8.2 & 708 \\
\hline Q6 & 463 & 65.4 & 245 & 34.6 & 708 \\
\hline Q7 & 267 & 37.7 & 441 & 62.3 & 708 \\
\hline Q8 & 422 & 59.6 & 286 & 40.4 & 708 \\
\hline Q9 & 315 & 74.6 & 107 & 25.4 & 708 \\
\hline Q10 & 330 & 78.2 & 92 & 21.8 & 708 \\
\hline
\end{tabular}

Table1: Summary frequency table for all questions.

\begin{tabular}{|c|c|c|c|c|c|}
\hline \multirow[t]{2}{*}{ Question } & \multicolumn{2}{|l|}{ Female } & \multicolumn{2}{|l|}{ Male } & \multirow[t]{2}{*}{$p$ value } \\
\hline & NO & YES & NO & YES & \\
\hline \multirow[t]{2}{*}{ Q1 } & 14 & 430 & 20 & 244 & \multirow[t]{2}{*}{0.00778} \\
\hline & $3.15 \%$ & $96.85 \%$ & $7.58 \%$ & $92.42 \%$ & \\
\hline \multirow[t]{2}{*}{ Q2 } & 92 & 352 & 89 & 175 & \multirow[t]{2}{*}{0.00013} \\
\hline & $20.72 \%$ & $79.28 \%$ & $33.71 \%$ & $66.29 \%$ & \\
\hline \multirow[t]{2}{*}{ Q3 } & 48 & 396 & 66 & 198 & \multirow[t]{2}{*}{0.00000} \\
\hline & $10.81 \%$ & $89.19 \%$ & $25.00 \%$ & $75.00 \%$ & \\
\hline \multirow[t]{2}{*}{ Q4 } & 357 & 87 & 190 & 74 & \multirow[t]{2}{*}{0.00961} \\
\hline & $80.41 \%$ & $19.59 \%$ & $71.97 \%$ & $28.03 \%$ & \\
\hline \multirow[t]{2}{*}{ Q5 } & 30 & 414 & 28 & 236 & \multirow[t]{2}{*}{0.07092} \\
\hline & $6.76 \%$ & $93.24 \%$ & $10.61 \%$ & $89.39 \%$ & \\
\hline \multirow[t]{2}{*}{ Q6 } & 142 & 302 & 103 & 161 & \multirow[t]{2}{*}{0.05713} \\
\hline & $31.98 \%$ & $68.02 \%$ & $39.02 \%$ & $60.98 \%$ & \\
\hline \multirow[t]{2}{*}{ Q7 } & 259 & 185 & 182 & 82 & \multirow[t]{2}{*}{0.00487} \\
\hline & $58.33 \%$ & $41.67 \%$ & $68.94 \%$ & $31.06 \%$ & \\
\hline \multirow[t]{2}{*}{ Q8 } & 157 & 287 & 129 & 135 & \multirow[t]{2}{*}{0.00040} \\
\hline & $35.36 \%$ & $64.64 \%$ & $48.86 \%$ & $51.14 \%$ & \\
\hline \multirow[t]{2}{*}{ Q9 } & 70 & 217 & 37 & 98 & \multirow[t]{2}{*}{0.50635} \\
\hline & $24.39 \%$ & $75.61 \%$ & $27.41 \%$ & $72.59 \%$ & \\
\hline \multirow[t]{2}{*}{ Q10 } & 61 & 226 & 31 & 104 & \multirow[t]{2}{*}{0.69173} \\
\hline & $21.25 \%$ & $78.75 \%$ & $22.96 \%$ & $77.04 \%$ & \\
\hline
\end{tabular}

Table 2: Statistics (Chi-square test): testing statistical difference between female and male (Sex) with respect to questions Q1- Q10.

their therapy. Of the total, $59.6 \%$ observed that possibility, women in $64.6 \%$, and men in $51.14 \%$ of cases, which was a statistically significant difference. The difference between age groups was also considerable, in particular in the age group to 35 years, where it was observed among both men and women (Tables $1,2,3$ ).

In response to the question of whether they had shared their observations with a doctor or a pharmacist, $74.6 \%$ of examinees gave an affirmative reply. As many as $78.2 \%$ of patients interrupted or changed the therapy without prior consultation with their pharmacist or doctor in an independent decision based on the information read in the patient leaflet (Table 1).

Table 4 shows inter-question analysis to discover deeper correlations and to explain a trend between reading the leaflet and knowing the meaning of the key terms. The Chi-square and Phi coefficient were used for all answers correlation testing. There is a statistically significant correlation between reading a leaflet and understanding the information, but more significant is the correlation between question Q8 (Have you ever found, in a patient leaflet, the information which made you think that the use of this drug would not be beneficial or safe for your therapy?) and Q 10 (Have you ever interrupted or changed your

\begin{tabular}{|c|c|c|c|c|c|c|c|}
\hline \multirow{2}{*}{$\begin{array}{l}\text { Ques- } \\
\text { tion }\end{array}$} & \multicolumn{2}{|l|}{$<35$} & \multicolumn{2}{|l|}{$35-65$} & \multicolumn{2}{|l|}{$>65$} & \multirow[t]{2}{*}{$p$ value } \\
\hline & NO & YES & NO & YES & NO & YES & \\
\hline \multirow[t]{2}{*}{ Q1 } & 65 & 149 & 19 & 409 & 7 & 59 & \multirow[t]{2}{*}{0.06342} \\
\hline & $30.37 \%$ & $69.63 \%$ & $4.44 \%$ & $95.56 \%$ & $10.61 \%$ & $89.39 \%$ & \\
\hline \multirow[t]{2}{*}{ Q2 } & 65 & 149 & 95 & 333 & 21 & 45 & \multirow[t]{2}{*}{0.03860} \\
\hline & $30.37 \%$ & $69.63 \%$ & $22.20 \%$ & $77.80 \%$ & $31.82 \%$ & $68.18 \%$ & \\
\hline \multirow[t]{2}{*}{ Q3 } & 38 & 176 & 63 & 365 & 13 & 53 & \multirow[t]{2}{*}{0.43372} \\
\hline & $17.76 \%$ & $82.24 \%$ & $14.72 \%$ & $85.28 \%$ & $19.70 \%$ & $80.30 \%$ & \\
\hline \multirow[t]{2}{*}{ Q4 } & 168 & 46 & 323 & 105 & 56 & 10 & \multirow[t]{2}{*}{0.20858} \\
\hline & $78.50 \%$ & $21.50 \%$ & $75.47 \%$ & $24.53 \%$ & $84.85 \%$ & $15.15 \%$ & \\
\hline \multirow[t]{2}{*}{ Q5 } & 10 & 204 & 37 & 391 & 11 & 55 & \multirow[t]{2}{*}{0.00693} \\
\hline & $4.67 \%$ & $95.33 \%$ & $8.64 \%$ & $91.36 \%$ & $16.67 \%$ & $83.33 \%$ & \\
\hline \multirow[t]{2}{*}{ Q6 } & 77 & 137 & 139 & 289 & 29 & 37 & \multirow[t]{2}{*}{0.16721} \\
\hline & $35.98 \%$ & $64.02 \%$ & $32.48 \%$ & $67.52 \%$ & $43.94 \%$ & $56.06 \%$ & \\
\hline \multirow[t]{2}{*}{ Q7 } & 134 & 80 & 270 & 158 & 37 & 29 & \multirow[t]{2}{*}{0.54473} \\
\hline & $62.62 \%$ & $37.38 \%$ & $63.08 \%$ & $36.92 \%$ & $56.06 \%$ & $43.94 \%$ & \\
\hline \multirow[t]{2}{*}{ Q8 } & 110 & 104 & 272 & 156 & 40 & 26 & \multirow[t]{2}{*}{0.01242} \\
\hline & $51.40 \%$ & $48.60 \%$ & $63.55 \%$ & $36.45 \%$ & $60.61 \%$ & $39.39 \%$ & \\
\hline \multirow[t]{2}{*}{ Q9 } & 43 & 67 & 61 & 211 & 3 & 37 & \multirow[t]{2}{*}{ * } \\
\hline & $39.09 \%$ & $60.91 \%$ & $22.43 \%$ & $77.57 \%$ & $7.50 \%$ & $92.50 \%$ & \\
\hline \multirow[t]{2}{*}{ Q10 } & 29 & 81 & 55 & 217 & 8 & 32 & \multirow[t]{2}{*}{0.40296} \\
\hline & $26.36 \%$ & $73.64 \%$ & $20.22 \%$ & $79.78 \%$ & $20.00 \%$ & $80.00 \%$ & \\
\hline
\end{tabular}

${ }^{*}$ Chi-square test for questions Q9 was statistically unreliable, because number of examinees is less than 5 in one category

Table 3: Statistics (Chi-square test): testing statistical difference between age groups with respect to questions Q1- Q10.

therapy due to a patient information leaflet without prior consultation with health care professionals?). Also there is significant correlation between Q3 and Q9 question explaining that the patient who knows what adverse effects their medicine can have in the most cases share their observations with a doctor or a pharmacist.

\section{Discussion}

\section{Principal findings}

In regard to frequent questions pharmacists encounter daily about medicines a patient has bought or has at home, many studies have assumed that the patients have not sufficiently read the patient leaflet, and therefore lack the required information about drug administration and potential side effects, interactions and contraindications. However, our results indicate that $95.2 \%$ of examinees read the leaflet prior to first use of the medicine, $83.9 \%$ are familiar with undesirable drug effects, $74.4 \%$ know the intended purpose of the drug, and $77.3 \%$ keep the package and patient leaflet until the therapy has been completed (Table 1). Moreover, the data show no statistically significant difference between men and women (Table 2), or between examinees of different ages in the regularity of reading the leaflet (Table 3 ). These data are encouraging and, initially, the patient appears to be safe and informed after reading the patient leaflet.

When the patient found in a leaflet, the information which made him think that the use of the drug would not be beneficial or safe for his therapy, he will interrupt or change this therapy without prior consultation with health care professionals in most cases. That is why is so important for a pharmacist to open an informative consultation, while patient is still in the pharmacy, to resolve all the concerns the patient may have. Competent pharmacist should not miss this opportunity to prevent the misunderstanding and interruption of the patient medicine therapy. 


\begin{tabular}{|c|c|c|c|}
\hline Chi-square test & Chi-square & Phi coefficient & $p$ value \\
\hline Q1 vs Q2 & 54,42 & $-0,28$ & $<0,001$ \\
\hline Q1 vs Q3 & 30,38 & $-0,21$ & $<0,001$ \\
\hline Q1 vs Q4 & 6,91 & 0,10 & 0,009 \\
\hline Q1 vs Q5 & 11,17 & 0,13 & 0,001 \\
\hline Q1 vs Q6 & 7,15 & 0,10 & 0,008 \\
\hline Q1 vs Q7 & 0,18 & 0,02 & 0,669 \\
\hline Q1 vs Q8 & 2,33 & 0,06 & 0,127 \\
\hline Q1 vs Q9 & 1,37 & $-0,04$ & 0,242 \\
\hline Q1 vs Q10 & 0,49 & 0,03 & 0,486 \\
\hline Q2 vs Q3 & 125,83 & 0,42 & $<0,001$ \\
\hline Q2 vs Q4 & 42,83 & $-0,25$ & $<0,001$ \\
\hline Q2 vs Q5 & 2,64 & $-0,06$ & 0,104 \\
\hline Q2 vs Q6 & 7,74 & $-0,10$ & 0,005 \\
\hline Q2 vs Q7 & 0,10 & $-0,01$ & 0,757 \\
\hline Q2 vs Q8 & 8,79 & $-0,11$ & 0,003 \\
\hline Q2 vs Q9 & 38,76 & 0,23 & $<0,001$ \\
\hline Q2 vs Q10 & 2,43 & $-0,06$ & 0,119 \\
\hline Q3 vs Q4 & 65,11 & $-0,30$ & $<0,001$ \\
\hline Q3 vs Q5 & 4,46 & $-0,08$ & 0,035 \\
\hline Q3 vs Q6 & 9,78 & $-0,12$ & 0,002 \\
\hline Q3 vs $Q 7$ & 0,71 & 0,03 & 0,399 \\
\hline Q3 vs Q8 & 20,92 & $-0,17$ & $<0,001$ \\
\hline Q3 vs Q9 & 49,04 & 0,26 & $<0,001$ \\
\hline Q3 vs Q10 & 11,68 & $-0,13$ & $<0,001$ \\
\hline Q4 vs Q5 & 3,61 & 0,07 & 0,057 \\
\hline Q4 vs Q6 & 3,06 & 0,07 & 0,080 \\
\hline Q4 vs Q7 & 2,60 & $-0,06$ & 0,107 \\
\hline Q4 vs Q8 & 3,31 & 0,07 & 0,069 \\
\hline Q4 vs Q9 & 27,86 & $-0,20$ & $<0,001$ \\
\hline Q4 vs Q10 & 4,56 & 0,08 & 0,033 \\
\hline Q5 vs Q6 & 43,63 & 0,25 & $<0,001$ \\
\hline Q5 vs Q7 & 1,90 & $-0,05$ & 0,168 \\
\hline Q5 vs Q8 & 0,03 & 0,01 & 0,873 \\
\hline Q5 vs Q9 & 0,39 & $-0,02$ & 0,532 \\
\hline Q5 vs Q10 & 0,14 & 0,01 & 0,708 \\
\hline Q6 vs Q7 & 15,81 & $-0,15$ & $<0,001$ \\
\hline Q6 vs Q8 & 2,11 & 0,05 & 0,146 \\
\hline Q6 vs Q9 & 7,65 & $-0,10$ & 0,006 \\
\hline Q6 vs Q10 & 4,07 & 0,08 & 0,044 \\
\hline Q7 vs Q8 & 4,79 & $-0,08$ & 0,029 \\
\hline Q7 vs Q9 & 4,54 & 0,08 & 0,033 \\
\hline Q7 vs Q10 & 1,58 & $-0,05$ & 0,209 \\
\hline Q8 vs Q9 & 66,46 & $-0,31$ & $<0,001$ \\
\hline Q8 vs Q10 & 212,67 & 0,55 & $<0,001$ \\
\hline Q9 vs Q10 & 69,63 & $-0,31$ & $<0,001$ \\
\hline
\end{tabular}

Table 4: Statistics (Chi-square test): inter-questions analysis (Q1- Q10).

\section{Meaning of the Study}

This study has shown that patients do not sufficiently understand the meaning of the basic terminology used in the patient leaflet. These data tell us how important it is for pharmacists to focus on informing patients about important facts about medicine dispensed in the pharmacy, and to avoid assuming that the patient has the necessary knowledge. A competent pharmacist should, during the conversation, evaluate to what extent a patient understands the leaflet by advising and warning about significant terms.

The question: "Do you know there are some situations in which the use of this drug is not beneficial?" examines the patient's knowledge of possible contraindications, i.e., excludes the possibility that a patient takes the drug in the case of contraindication. The pharmacist should, while performing pharmacy consultation, check whether a patient is taking other medications and if the patient understands the possible interactions. In that way, the patient will pay attention to drug combinations, and to the influence of food on drugs.

The fact that $74.6 \%$ patients reported that they refer to a doctor or pharmacist for advice in case of doubts after reading the patient leaflet represents an extremely valuable outcome of this study (Table 1). The mandatory text of advertisements, which refers patients to read the leaflet and consult a doctor or pharmacist for further questions, is implied to have a significant influence on patient behaviour. However, it also indicates something else: at the time of first dispensing of the medicine, the patient is not sufficiently informed about a medicine. Only after reading the leaflet, in as many as $59.6 \%$ cases (Table 1 ), the patient develops doubts as to whether to take the drug. This refers especially to the necessity of developing pharmacist competencies regarding consultations and education of patients, and emphasizes the skill of asking questions to collect information. This is also important due to the high probability $(74.6 \%)$ that a patient will return if the initial data received during the first contact with a pharmacist is insufficient. In such a case, the pharmacist will be able to influence significantly the compliance and safety of patients.

\section{Comparison to Other Studies}

Some authors have evaluated that approximately half of patients do not use their prescribed medications properly [13]. Patients who are well informed about treatment options, possible risks and benefits of a therapy will cooperate better, and consequently the treatment outcome will be better [14]. Studies also show that reading the patient leaflets can increase concerns in patients [15], and the results of this study suggest that patients will, in the case a drug is possibly not the safest choice for them, change or interrupt their therapy independently in as many as $78.2 \%$ cases, (Table 1) regardless of their age or gender (Tables 2, 3).

The interruption of a therapy may imply a very severe outcome in some patients. An abrupt interruption of the administration of some psychotropic medicines can result in suicide [16], while interruption in the administration of antimicrobial agents will cause the spread of infection. Interruption in the treatment of chronic disease therapy, such as diabetes, essential hypertension or asthma, will exacerbate the patient's clinical status, and impair blood glucose levels, blood pressure, or maximum lung expiratory volume. Therefore, apart from patient's incompliance, the treatment outcomes will be less successful.

The fact that as many as $38 \%$ patients do not know the difference between the terms "contraindication" and "side effect" is worrisome. If a patient does not understand, while reading that leaflet, that contraindications are the states in which he/she should not use the medicine, it is very likely that they could still take the medicine. Therefore, it would be more efficient to state the following in a leaflet "When you should not take the drug?" instead of "Contraindications". Asking questions at the time of first dispensing is especially important in order to exclude the possibility of taking medicines with a contraindication. These could be questions such as, "Do you have stomach troubles, Are you pregnant, Do you smoke, Are you taking any other medications, Do you have any allergies?" etc. Questions often asked by pharmacists, such as "Have you previously taken this medication?" or "Do you know everything about the medicine you are taking?" will not provide precise answers that can allow the pharmacist to identify the real need for information. 
In recent years, efficient programs for the evaluation of pharmacist competencies have been applied. One such model has been supported via the General Level Framework (GLF) in Great Britain, developed within CoDEG (Competency Development and Evaluation Group) in 2005 [17]. The document contains a detailed description of actions, skills and knowledge that should be applied by a pharmacist in delivering competent pharmaceutical patient care, such as the identification of need for information, as well as quality of medicine information given to a patient $[18,19]$. Trials, modified to GLF, have also been conducted in Croatia about the development of these competencies. The initial results show that pharmacists rarely (in $21-50 \%$ cases) succeed in identifying their patients' need for information, and they usually (51-84\%) provide exact and reliable information on medicines. These results clearly show that these competencies are still to be developed [12]. Initiatives to improve patient safety have a high priority among health professionals in most developed countries. Given that the assessment of patient safety issues relies mainly on case-based methodologies, there is a need for evidence-based methods to ensure and develop patient safety [20].

While communicating with a pharmacist, a patient can fail to ask questions about the disease or therapy because the pharmacist assumes that the patient has sufficient knowledge. In conversation, openended questions should be asked to help a patient express himself. It is important to check that the patient understands his current situation, what he knows about the disease, his doubts or difficulties in receiving therapy and the reasons for possible incompliance, fears, worsening of the clinical state or other negative treatment outcomes. Enough time should always be left to clarify anything that is unclear and to listen. When dispensing medicines or other medicinal preparations, a pharmacist most frequently gives information patients consider important, and also answers their questions.

The data suggest the conclusion that patients read the patient information leaflet and are acquainted with the purpose and undesirable effects of a medicine they use. However, comprehension of the enclosed patient information leaflet is questionable with regard to the high prevalence of not knowing as many as two of the three examined terms. In addition, as many as one-third of examinees are not prone to consulting professionals, and that they change or terminate their therapy independently, which especially refers to the younger population. The data indicate that more attention should be paid in communication with men and the younger population in general.

\section{Unanswered Questions and Future Research}

The role of pharmacists as consultants should also be stressed, as these data indicate that informing patients about medicinal products through a leaflet could be insufficient for proper understanding and successful therapy. Identification of patients' needs for information and education and consultation about the proper use of medicines is a key competency of pharmacists that should be developed further. This is definitely significant for the patient's feeling of satisfaction and safety.

This study did not distinguish between prescription-needed and over the counter (OTC) drugs, or long term (chronic) versus short term (acute) medication. There is assumption that patients using a drug for the first time or taking a prescribed medication are likely to read the leaflets more often and more carefully, particularly because they think that OTC drugs are safer. This should be further explored and discussed in future studies. Some patients never read or cannot read the instructions and warnings in the patient information leaflet, and therefore completely rely on the pharmacist's verbal instructions. Nevertheless, if a patient notices that the given verbal instructions do not correspond to the written instructions or some other written information about a medicine, the result will be develop of a feeling of distrust towards the pharmacist. When replying, answers should be clear, accurate and substantial, expressed using an easy-to-understand vocabulary, clear and precise. Of course, the source of information should be checked. A competent pharmacist takes a critical approach to advertising brochures and relies on a medicine based on proven and expert literature. Accuracy of the given information should certainly be assessed, as this is occasionally the only information a patient receives.

The patient information leaflet should be written in language that the patient can easily understandable, with modified letter size, terminology, and quantity of important data. The combination of written information and consultation with competent pharmacist is shown to be the safest for a patient. The opportunity to promote the responsible and rational use of medicines should not be looked over by regulatory authorities and drug manufacturers.

\section{Acknowledgements}

This research was supported by the Atlantic Farmacia Education Centre Croatia's largest pharmacy chain.

\section{References}

1. Bulajić M (2010) Communication in crisis (in Croatian). Medix: Zagreb 86

2. Randall S, Stafford MD (2008) Regulating Off-Label Drug Use - Rethinking the Role of the FDA. N Engl J Med 358: 1427-1429.

3. Shrank W, Avorn J, Rolon C, Shekelle P (2007) Effect of Content and Format of Prescription Drug Labels on Readability, Understanding, and Medication Use: A Systematic Review Online. Ann Pharmacother 41: 783-801.

4. Hughes L, Whittlesea C, Luscombe D (2002) Patient's knowledge and perception of side-effects of OTC medication. J Clin Pharm Ther 27: 243-248.

5. Wood DM, English E, Butt S, Ovaska H, Garnham F, et al. (2010) Patien knowledge of the paracetamol content of over-the-counter (OTC) analgesics, cough/cold remedies and prescription medications. Emerg Med J 27: 829-833.

6. Shrank WH, Avorn J (2007) Educating Patients About Their Medications: The Potential And Limitations Of Written Drug Information. Health Affairs 26: 731 740

7. Gajski L (2009) Drugs or story of deception (in Croatian). Pergamena: Zagreb.

8. Beers MH, Berkow R (2004) Drug therapy in the Elderly. The Merck manual of diagnosis and therapy. Merck research laboratories.

9. Bardel A, Wallander MA, Svardsudd K (2000) Reported current use of perscription drugs and some of its determinants among 35-65 year-old women in mid-Sweden. J Clin Epidemiol 53: 637-643.

10. Burak LJ, Damico A (2000) College Students' Use of Widely Advertised Medications. Journal of American College Health 49: 118-121.

11. O'Connor E, Coates HM, Yardley IE, Wu AW (2010) Disclosure of patient safety incidents: a comprehensive review. Int J Qual Health Care 22: 371-379.

12. Meštrović A, Staničić Z, Hadžiabdić MO, Mucalo I, Bates I, et al. (2011) Evaluation of Croatian Community Pharmacists' Patient Care Competencies Using the General Level Framework. Am J Pharm Educ 75: 36.

13. Townsend A, Hunt K, Wyke S (2003) Managing multiple morbidity in mid-life: a qualitative study of attitudes to drug use. BMJ $327: 837$

14. Coulter A (2002) After Bristol: putting patients at the centreCommentary: Patient centred care: timely, but is it practical? BMJ 324: 648

15. Vinker S, Eliyahu V, Yaphe J (2007) The effect of drug information leaflets on patient behavior. IMAJ 9: 383-386.

16. American Psychiatric Association (2007) Practice guidelines for the treatment of patients with major depressive disorder. 2nd edition.

17. Mills E, Farmer D, Bates I, Davies G, Webb D, et al. (2005) Development of an evidence led competency framework for primary care and community pharmacists. Pharma J 275: 48-52. 
Citation: Meštrović A, Gjergja A, Košiček M (2012) Patients Need a Competent Pharmacist for a Safe and Successful Therapy. Adv Pharmacoepidem Drug Safety 1:104. doi:10.4172/2167-1052.1000104

Page 6 of 6

18. Antoniou S, Webb DG, McRobbie D, Davies JG, Wright J, et al. (2005) A controlled study of the general level framework: Results of the South of England competency study. Pharmacy Education 5: 201-207.

19. Coombes I (2009) A Competency Framework for Pharmacy Practitioners to Provide Minimum Standard of Pharmaceutical Review - The General Level
Framework Handbook. Safe Medication Practice Unit Queensland Health, Adopted from NHS London and South East - CoDEG, Herston, 2nd edition.

20. Kristensen S, Mainz J, Bartels P (2009) Selection of indicators for continuous monitoring of patient safety: recommendations of the project 'safety improvement for patients in Europe'. Int J Qual Health Care 21: 169-175.
Submit your next manuscript and get advantages of OMICS Group submissions

Unique features:

- User friendly/feasible website-translation of your paper to 50 world's leading languages

Audio Version of published paper

Digital articles to share and explore

Special features:

- 100 Open Access Journals

10,000 editorial team

21 days rapid review process

Quality and quick editorial, review and publication processing

- Indexing at PubMed (partial), Scopus, DOAJ, EBSCO, Index Copernicus and Google Scholar etc

- Sharing Option: Social Networking Enabled

- Authors, Reviewers and Editors rewarded with online Scientific Credits

- Better discount for your subsequent articles

Submit your manuscript at: www.omicsonline.org/submission 